\title{
Integrating CSR with Business Strategy: A Tension Management Perspective
}

\author{
Jaakko Siltaloppi ${ }^{1} \cdot$ Risto Rajala $^{1} \cdot$ Henri Hietala ${ }^{1,2}$
}

Received: 3 October 2017 / Accepted: 1 July 2020 / Published online: 18 August 2020

(c) The Author(s) 2020

\begin{abstract}
Integrating corporate social responsibility (CSR) into a for-profit organization's business activities is fraught with tensions. This paper reports a case study of a construction company, exploring how different tensions emerged to challenge companylevel aspirations for strategic CSR integration. The study identifies three types of persistent CSR tensions and four management practices, discussing how the management practices led the organization to navigate CSR tensions in both active and defensive ways. Furthermore, the study explicates why the case company succeeded in integrating CSR into formal business strategy and shared attitudes but struggled with CSR integration in the domain of day-to-day operations. The paper contributes to the CSR literature by developing a tension-centric perspective on CSR development. It highlights the necessity of tension navigation at both the organizational and the action levels, the key role of active (as opposed to defensive) navigation of CSR tensions, and the importance of alignment between organizational and action levels in navigating tensions for sustaining strategic focus on CSR over time.
\end{abstract}

Keywords Corporate social responsibility $\cdot$ CSR tensions $\cdot$ Strategic CSR integration $\cdot$ CSR development $\cdot$ Case study

\section{Introduction}

With a growing emphasis on corporate social responsibility (CSR), companies must decide how to integrate CSR into their organizational strategy. For most companies, CSR has been a tool for improving business performance (e.g., Lindgreen et al. 2009; Weaver et al. 1999a) through initiatives that are unconnected with the business strategy, such as charities or PR programs (Husted 2003; Weaver et al. 1999b). While enabling the cultivation of external legitimacy (e.g., Crilly et al. 2012), the problem with such a peripheral approach to CSR is that it may not generate the best societal or business outcomes (Halme and Laurila

Jaakko Siltaloppi

jaakko.siltaloppi@aalto.fi

Risto Rajala

risto.rajala@aalto.fi

Henri Hietala

henri.hietala@aalto.fi

1 School of Science, Aalto University, P.O. Box 15500, 00076 Aalto, Finland

2 CGI Finland Ltd., Helsinki, Finland
2009). An integrated approach is needed instead, which integrates CSR into the company's day-to-day activities, core competencies, shared understandings, and strategic decisions (Aguinis and Glavas 2013; Basu and Palazzo 2008; Brooks 2005).

The integrated approach to CSR is essential for leveraging the potential synergies between social and business agendas (e.g., Gao and Bansal 2013), but calls for companies to embed CSR into organizational culture (Maon et al. 2010) and view it as an opportunity for innovation (Porter and Kramer 2006). Given the contradictions between economic and societal demands (Margolis and Walsh 2003), companies attempting to integrate CSR into their business strategy and operations also expose themselves to internal CSR tensions that require systematic managerial attention (Hahn et al. 2015; Ozanne et al. 2016; Smith et al. 2013). Thus, tension management becomes crucial for the integration of CSR into business strategy (Hahn et al. 2015).

However, despite insightful conceptual studies, we continue to have a limited understanding of the management of CSR tensions during the strategic CSR integration process (Hahn et al. 2018; Maon et al. 2010). To fill this gap in the knowledge, we investigated the management of CSR tensions during a strategic CSR integration process through 
a qualitative single-case study in a European construction company, "SmartCo." Since 2009, SmartCo has undergone a radical strategic transition that placed CSR and ethical values at the center of its business strategy. While the transition allowed SmartCo to challenge the construction industry's adverse contracting practices, its focus on short-term value, and the widespread involvement in the black economy, it also generated a variety of internal CSR tensions that called for managerial efforts to allow the organization to balance between business and CSR targets.

By investigating the navigation of CSR tensions at SmartCo, this study makes three main contributions to the CSR literature. First, it improves our understanding of the nature of CSR tensions at the core of the CSR development process, as well as the various management practices that allow companies to address the CSR tensions. Second, this study develops new knowledge of the ways in which tension management contributes to strategic CSR integration. Identifying recognition and evasion as ways of navigating tensions at the organizational level, as well as adjustment, confrontation, and regression at the action level, the findings highlight the crucial role of active as opposed to defensive navigation of CSR tensions, and call for alignment in navigating the tensions across the organization. Third, this study extends the predominantly conceptual work on the tension-based integrative view of CSR. Specifically, our work deepens the understanding of the role of management's interventions for supporting the navigation of persistent CSR tensions.

This article is structured as follows. We begin by establishing the theoretical background of this study by distinguishing peripheral from integrated approaches to CSR, and by positioning persistent tensions as the core challenge of strategic CSR integration. We then describe our empirical inquiry of SmartCo and explain the analytical process of our qualitative study. Thereafter, we present our findings on the management of CSR tensions, and synthesize the findings to explain how the navigation of CSR tensions through active and defensive means contributed to strategic CSR integration. We conclude by situating our contributions within the CSR development literature, emphasizing the navigation of CSR tensions as a central element in strategic CSR integration, along with providing implications for managers, and describing the limitations and potential avenues for future research.

\section{Literature Review}

\section{From Peripheral CSR to Strategic CSR Integration}

A widely accepted premise in CSR literature is that companies have societal and environmental obligations that go beyond shareholder interests and legal compliance. Besides this premise, however, the perspectives taken to CSR vary significantly (e.g., Basu and Palazzo 2008; Carriga and Mele 2004; Lantos 2001; McWilliams et al. 2006), including the definition of CSR and its distinction from related concepts such as corporate sustainability (Bansal and Song 2017; Montiel 2008). Here, we align with Carroll's (1979) view of CSR as embodying the economic, legal, ethical, and discretionary obligations a business has to society. In addition to emphasizing CSR as going beyond minimum legal requirements, Carroll (1979) provides a conceptual basis for analyzing the differences between companies regarding the social issues they address, as well as their responsiveness to these social issues (see also Lindgreen et al. 2009; Weaver et al. 1999a). This is important because the outcomes of CSR initiatives depend on their implementation (Halme and Laurila 2009).

In this paper, we foreground the distinction between a peripheral and integrated approach to implementing CSR (e.g., Aguinis and Glavas 2013; Weaver et al. 1999b). Companies that have adopted the peripheral approach to CSR separate the activities and initiatives focused on social issues from the core business activities to satisfy external expectations. For example, companies may outsource CSR through charitable contributions or other forms of philanthropy (Husted 2003), which enables them to garner external legitimacy while maintaining an internal focus on core business processes and financial performance (Halme and Laurila 2009). Such CSR activities are driven by external incentives and specific stakeholder pressures (Weaver et al. 1999b; Wheeler et al. 2002). For this reason, they often produce fragmented CSR activities that lack internal consistency (Yuan et al. 2011) and consequently fail to positively impact either the business or societal outcomes of the company (Porter and Kramer 2002, 2006).

In contrast, the integrated approach incorporates CSR into the organization's core activities, structures, and policies (Aguinis and Glavas 2013; Weaver et al. 1999b; Yuan et al. 2011). While more complicated than the implementation of peripheral initiatives, due to the need to legitimate CSR as an essential part of the company (Smith et al. 2013), the integrated approach may enable companies to improve their economic and social performance by tapping into the synergies between business and societal agendas (Gao and Bansal 2013; Halme and Laurila 2009). In this paper, we focus specifically on strategic CSR integration, which we define as an organization-wide change process that integrates CSR not only into the company's day-today activities, routines, and policies (Brooks 2005), but also into its strategic decision-making, core competencies (Aguinis and Glavas 2013), and organizational culture (Jones et al. 2007; Maon et al. 2010). The moral development of a company's culture (e.g., Reidenbach and Robin 1991) plays an important part in strategic CSR 
integration because it has a constitutive impact on how the company perceives its environment and balances between stakeholder expectations and business demands (Basu and Palazzo 2008; Hahn et al. 2014). In addition, culture directs how the organization operationalizes its strategy into specific policies and practices (Berger et al. 2007), how responsive and open it is to stakeholder demands (Jones et al. 2007), and how it builds relationships among internal and external stakeholders (Brickson 2007).

Strategic CSR integration involves multiple intermediary stages between rejecting CSR and embedding it into strategy and organizational culture (e.g., Mirvis and Googins 2006; Reidenbach and Robin 1991). For example, in their synthesis of the CSR development literature, Maon et al. (2010) identify three cultural phases and seven stages in the integration of CSR, which involve distinct patterns across the organizational dimensions of shared knowledge and attitudes, strategy, and day-to-day operations. Each stage also requires its own organizational patterns in relating business and CSR (Yuan et al. 2011), and introduces distinct managerial demands. For example, the integration of CSR through a code of ethics may draw management attention to sanction misbehavior and create struggles with the empowerment of employees. In contrast, the integration of CSR into the company's values may require efforts to counter internal disagreements and the abuse of autonomy by influential individuals (Rossouw and van Vuuren 2003).

Although the literature on CSR development informs us about the stages and organizational dimensions of strategic CSR integration, there is much less research on how firms manage this transition (for exceptions, see Ingham and Havard 2017; Maon et al. 2009). Empirical literature has notably overlooked the trade-offs and tensions in strategic CSR integration (Hahn et al. 2010; Van der Byl and Slawinski 2015), which derive from the incompatibility between economic and social targets (Margolis and Walsh 2003). While latent when integrated peripherally, strategic CSR integration exacerbates these tensions by forcing the organization to strive for both goals simultaneously in its core processes (e.g., Hahn et al. 2015; Ozanne et al. 2016; Smith et al. 2013). For example, attending simultaneously to social and economic demands exerts a continuous tension on the sensemaking of top management as it increases the number and complexity of decision-making attributes (Hahn et al. 2014). Moreover, combining economic and social performance in inter-organizational relationships, organizational structures, competences and day-to-day activities entails the coexistence of incompatible principles and practices that potentially undermine strategic CSR integration (Basu and Palazzo 2008; Scherer et al. 2013; Smith et al. 2013). Hence, to understand the process of strategic CSR integration, we must focus on the management of CSR tensions.
A Tension Management Perspective of Strategic CSR Integration

CSR tensions are intra-organizational tensions that arise from efforts to implement the ideas, policies, and practices associated with CSR simultaneously with the pursuit of business targets. The literature offers various perspectives on CSR tensions. For example, the paradox perspective (e.g., Smith and Lewis 2011) suggests that CSR tensions arise from competing goals and strategies between CSR and business (performing tensions), competing organizational designs (organizing tensions), divergent identities among organizational groups regarding their adherence to social responsibility (belonging tensions), and different temporal horizons and demands of change between business and CSR (learning tensions). Each dimension entails distinct demands for tension management (Ozanne et al. 2016; Smith et al. 2013).

Alternatively, Hahn et al. (2015) discuss CSR tensions in terms of level, change, and context. In their conceptualization, the tensions of level derive from the different connotations of sustainability at the individual, firm, and systemic levels. For example, what seems an appropriate response to a social issue for an individual may contradict organizational-level CSR goals. Tensions of change, in turn, originate in the changes required by strategic CSR integration. Here, contradictions may arise in selecting the most urgent domain for change, or in deciding how the organization should effect change. Finally, tensions of context are caused by contradictions between the short-term view of economic decision-making, and the global externalities and long-term implications of these decisions. For instance, they pertain to justifying strategic investments into CSR agendas that have considerably longer time frames and higher uncertainty than business investments.

The literature outlines two approaches to managing CSR tensions (Van der Byl and Slawinski 2015). In one approach, a company may seek to avoid the tensions altogether, either by prioritizing business targets ("trade-off") or by selecting the elements of CSR so that they don't interfere with business performance ("win-win"). Keeping CSR peripheral, this strategy limits the attainable societal benefits but may allow the organization to garner external legitimacy for its CSR programs (de Jong and van der Meer 2015). In the other approach, a company may strive for deeper integration between social and economic targets without favoring one over the other. This approach requires the company to purposefully embrace the ensuing tensions as inherent parts of its commitment to responsible business (Gao and Bansal 2013), and to find ways to balance or reconcile those tensions through separation or synthesis (Hahn et al. 2015).

The overarching challenge with the latter is that the CSR tensions persist over time and make actions by one 
set of principles difficult (e.g., Poole and Van de Ven 1989; Putnam et al. 2016; Smith and Lewis 2011). In response, companies need efforts both at the organizational and action levels to legitimize and balance CSR with business targets (Hengst et al. 2020). For example, at the organizational level, new capabilities are needed to defuse the tensions associated with a responsible business (Ivory and Brooks 2018; Vallaster et al. 2019), along with new hybrid structures and support systems (Smith et al. 2013). At the action level, decision-makers need to adopt complex rationales and decision-making frames to deal constructively with the tensions (Hahn et al. 2014), and contradictory policies and managerial practices may be needed to advance CSR and business goals simultaneously (Scherer et al. 2013).

While providing insights into the nature and resolution of CSR tensions, the conceptual nature of the CSR tension literature calls for a careful empirical investigation of the practices through which CSR tensions are managed in strategic CSR integration (e.g., Van der Byl and Slawinski 2015). Thus, the rest of this paper explores the management of CSR tensions during the strategic CSR integration process.

\section{Research Methods}

\section{Context}

To advance the research on strategic CSR integration, we conducted a qualitative single-case study on "SmartCo," a medium-sized construction company in Finland. We examined SmartCo's change process from 2009 to 2017, during its transformation from a business-focused company with fewer than 30 employees to a company that defined its business strategy through ethical values and that employed nearly 300 people. This growth was driven by a succession of cumulative strategic changes, which shaped both SmartCo's business visions and its strategic commitment to CSR (see Table 1). Hence, unlike a planned change initiative in a large organization (e.g., Ingham and Havard 2017; Maon et al. 2009), SmartCo offers unique insights into an organic change process through which ethical values came to define the company's identity and business strategy, as well as its efforts to advocate CSR through its core business practices.

The change process began in 2009 with the appointment of a new CEO who redefined the company's business strategy as "service construction," and set out to rectify industry-wide issues with poor quality, lack of transparency, and adversarial relationships with emphasis on building longterm collaboration with customers and other stakeholders. Although CSR was not yet explicitly on the strategic agenda, the strategy made SmartCo more sensitive to its immediate stakeholders (clients, sub-contractors, users). In 2012, SmartCo's commitment to CSR was made explicit with the 
introduction of ethical values and the adoption of a formal code of ethics in the wake of a publicized case of bribery in one of SmartCo's construction projects.

From 2014 onwards, SmartCo started to explicate its strategy by practicing the ethical values of transparency, trust, and responsibility. Instead of being isolated from strategic objectives, these values were evoked in communications regarding the company's strategic visions and adopted by organization members as a basis for making sense of their shared organizational identity. Furthermore, the creation of new business units (focused on the development of new housing and service concepts) and internal ventures (focusing on digital solutions as basis of new collaboration models) helped embed the ethical values and societyimproving mission into business development. For example, one internal venture set out to build a platform for resident communities to facilitate interaction, sharing, and co-living as solutions to the unwanted effects of urbanization and rising costs of living.

When reflected against the organizational dimensions of CSR development (Maon et al. 2010), evident changes unfolded during the study period, which makes SmartCo a relevant case for investigating strategic CSR integration. In the dimension of shared attitudes and understandings, SmartCo shifted from ignoring CSR to perceiving the ethical values as central to its existence. With formal strategy, the company moved from a narrow customer focus to define the ethical values and principles as the basis of competitive advantage, and implemented this strategy through new business units and internal ventures. In the operational dimension, SmartCo effected a formal code of ethics, which provided a common policy and guideline for behavior in accordance with the company's values.

In addition, SmartCo is a compelling case due to its industry setting, which is fraught with ethical issues, such as adversarial contracting practices, lack of transparency, short-term value focus, and widespread problems with the black economy (e.g., Adnan et al. 2012; Jones et al. 2006;
Lohne et al. 2015). Coupled with the significance of the industry in shaping the structure, health and safety of the urban environment, the economy of households, and the ecological footprint of societies, improving the understanding of CSR integration in this context is crucial for the advancement of societal improvements through the contributions of for-profit companies.

\section{Empirical Data}

We investigated the strategic CSR integration process in SmartCo using documents, interviews, and observations (Table 2). Our document database consists of internal documents on the planning and execution of the new strategy within the executive group. We also examined internal communications such as PowerPoint presentations, leaflets, and guidelines for internal processes, as well as public documents such as annual reports, public presentations, and research reports. We accessed the materials through our contact person in the company, who is also the third author of this paper. In total, our document database consists of 203 documents, ranging from a few pages or slides to research reports exceeding 100 pages. We complemented this database with an examination of press releases available through the company website, which describes key events in SmartCo's history since 2012. The documents enabled us to explore the evolution of formal representations of CSR and ethical values as part of the business strategy and to trace the development of these representations over the study period.

We interviewed people in different roles and positions in the organization to gain a detailed understanding of the CSR integration process, the associated tensions, and ways of balancing and reconciling these tensions. We conducted two rounds of interviews (see Appendix for more details). In 2015, we began with 17 interviews with top- and midlevel managers representing the company's business units (construction business, pipe renovations, project consultation, housing business) to gain an overall understanding of

Table 2 Sources of empirical data

\begin{tabular}{|c|c|c|}
\hline Source of data & Description & Use in data analysis \\
\hline Documents & $\begin{array}{l}\text { 2009-2017: Strategic plans and presentations, meeting } \\
\text { minutes, formal guidelines, leaflets, annual reports, } \\
\text { media articles, press releases, } N=203 \text {. }\end{array}$ & $\begin{array}{l}\text { Insights into the evolution of SmartCo's formal strategy } \\
\text { and commitment to corporate responsibility. }\end{array}$ \\
\hline Interviews & $\begin{array}{l}\text { Executive group members, middle managers, and project } \\
\text { managers, } N=32 \text {. }\end{array}$ & $\begin{array}{l}\text { Understanding informants' experiences of CSR tensions } \\
\text { and their management throughout the strategic change } \\
\text { process. }\end{array}$ \\
\hline Outsider observations & $\begin{array}{l}\text { Informal meetings, strategy workshops, observation of } \\
\text { public events, } N=14 \text { (2014-2017). }\end{array}$ & $\begin{array}{l}\text { Understanding managers' and employees' experiences of } \\
\text { CSR tensions and commitment to the responsible busi- } \\
\text { ness strategy. }\end{array}$ \\
\hline Participant observation & $\begin{array}{l}\text { 2012-2017: Participation in strategy development (one of } \\
\text { the authors). }\end{array}$ & $\begin{array}{l}\text { Triangulation of findings from interviews and outsider } \\
\text { observations; insights into the resolution and manage- } \\
\text { ment of CSR tensions during strategic change. }\end{array}$ \\
\hline
\end{tabular}


the company's strategic change process and CSR integration. Because the company did not have a dedicated CSR person or team, we pieced together our understanding on this topic from multiple informants holding different roles within the organization, from marketing and sales to HR, strategy development, technical development, and construction project management. In the second interview round in 2017, we extended this inquiry to focus on the emergence and evolution of the ethical values as part of the company strategy. In addition to interviewing selected key informants for the second time, we added informants from the company's digital business unit and its internal ventures introduced in 2016. An additional 15 interviews deepened the insights developed through the first interview round and generated new insights into the evolution of the strategic CSR integration process since 2015.

We selected our informants from the top management team first and used snowball sampling thereafter to identify informants relevant to our inquiry. In both interview rounds, we used a thematic, semi-structured interview guide, which we updated between the interview rounds to shift attention from the strategic change process to CSR and ethical themes. In both series of interviews, we consciously refrained from imposing our own structure on the discussion. Adopting an interactionist approach (Silverman 1993), we allowed each interview to unfold according to the narrative and insights of the informant to gain an in-depth understanding of the informant's views of the company.

We also draw on two types of observations. Two of the authors observed 14 events either involving or led by SmartCo's presentation of their business, future visions, and ethical orientation and recorded their observations in a field diary. Altogether, the field diary comprises approximately 23 pages and 7000 words of detailed notes used as the material in the analysis. By involving personnel from across the organization, these observations helped us understand the company's commitment to CSR at a more granular level, especially by offering insights into the ways in which the management framed CSR as part of the strategy, as well as by revealing the experiences of organization members concerning these topics. Thus, the outsider observations helped us understand the persistence of CSR tensions in the organization, and to gauge the success of the adopted managerial means to rein in these tensions.

We also used participant observation; the third author worked as a consultant for strategy development at SmartCo from 2012 to 2014 and was a member of the executive group between 2014 and 2018. In the latter role, the third author participated in strategy development and HR management. The third author offered first-person experiences and insights from the top level of the organization, which we discussed with the research team on numerous occasions from the beginning of 2015. Four of these discussions were structured as formal interviews, recorded, and transcribed for analysis. We also had several informal discussions around the emerging findings of this paper. Notably, the first two authors were responsible for conducting data analysis; the participant observations were integrated into the analytical process primarily as a point of reflection for the emerging findings through joint discussion, complementing the primary data sources (i.e., documents, interviews, outsider observations).

\section{Data Analysis}

This rich data enabled us to examine how the process of strategic CSR integration unfolded in SmartCo. We began the analysis by developing a general understanding of the strategic change process at SmartCo. We used the publicly available documents as well as the first round of interviews to construct a detailed timeline of key events and changes. In addition, we wrote brief memos about the company's business units and offerings to gain a more structured understanding of the company's strategy.

With our detailed understanding of the case organization, we then turned our analytical focus to the process of strategic CSR integration. We used grounded theory building (e.g., Strauss and Corbin 1998) to construct an inductive, data-driven understanding of the emergence and management of CSR tensions at SmartCo. We began by analyzing the empirical material to identify the salient CSR tensions and management practices used to balance these tensions. For both elements, we followed a similar analytical process: While reading the empirical material, we coded the segments discussing either the tensions or managerial strategies using the informants' own words or expressions. This produced a long list of "in-vivo" codes that concisely described the CSR tensions and managerial actions. As the number of in-vivo codes grew, we turned our attention from assigning to comparing the codes to condense our "raw" observations through the data aggregation process discussed by Gioia et al. (2013). Here, we distilled the number of concepts and expressions into a more manageable set of first-order codes, which retained a close connection to the empirical material while capturing parsimoniously the distinct aspects of CSR tensions and managerial efforts. With CSR tensions, we used two criteria to organize and prune the initial in-vivo codes (Smith 2014): that the issue described was salient in SmartCo and that it involved a tension between business and CSR agendas. Here, we also fused overlapping in-vivo codes. For example, the code "CSR behaviors lag spoken values" fused the in-vivo codes of "slow progress with strategy enactment" and "building external hype without internal reality." With managerial actions, we similarly combined overlapping observations and reflected the emerging first-order codes against the identified CSR tensions to judge their relevance. For example, we omitted codes linked to the facilitation of organizational growth. As a result, we arrived at a total of 24 first-order codes. 
Overlapping with the previous phase, we started to compare the emerging first-order codes through axial coding (Strauss and Corbin 1998) to identify the properties and dimensions of the emerging CSR tensions and management practices that were relevant to the CSR integration process. We, therefore, moved from a descriptive to a theoretical mode of analysis (Gioia et al. 2013), iterating between empirical data, first-order codes, and the emerging secondorder themes to explain the unfolding of the strategic CSR integration process. When there were disagreements over interpretations of the empirical material between the two authors responsible for the analysis, the emerging codes along with underlying quotes were examined and discussed until arriving at a mutually satisfactory interpretation. While basing the emerging categories on data-driven observations, in the final stages of the axial coding procedure, we also compared our emerging groups of tensions and management practices with the literature to clarify their conceptual boundaries and underlying mechanisms. Thus, we brought an abductive element to the analysis (e.g., Denis et al. 2001), which anchored our analysis more firmly in the literature. This process resulted in three aggregate types of CSR tensions, and four types of management practices through which the tensions were balanced. This process of data aggregation is summarized in the data structure in Fig. 1, with empirical support for the categorization presented in Tables 3, 4, and 5 .

In the last phase of the analysis, we zeroed in on these aggregate themes to understand how the identified management practices contributed to the reconciliation of these tensions and, thus, to the strategic integration of CSR. Here, we started by examining the excerpts of empirical material associated with the CSR tensions and management practices and linked the two on the timeline of the case (see Fig. 2). After that, we examined the empirical material to identify examples and passages that offered insights into the ways in which the

\section{First-order codes}

- Inherited industry attitudes contradict values

- Ethical values lack concrete guidelines

- Strategic visions confusing

- Variation in compliance between individuals, projects

- Management cuts corners

- CSR behaviors lag spoken values

- Performance guidance constricts the realization of visions

- Tolerating unethical practices to protect cash flows

- Diverging strategic investment priorities

- Gap between projects and HQ

- Communicating values

- Explicating business strategy with ethical values

- Maintaining internal dialogue and debate on strategic direction

- CEO's personal values, presence

- Transparency with ethical issues

- Setting example with visible problem resolution

- Introducing formal ethical code

- Ethical principles as part of labor contract

- New KPIs with stakeholder focus

- Systematization of processes and contracts

- Recruitment based on employees' compatible values

- Compulsory ethical training

- Organization-wide events with CSR focus

- Endorsement for learning, innovation

\section{Second-order themes \\ categories}

Past understandings

incompatible with future visions

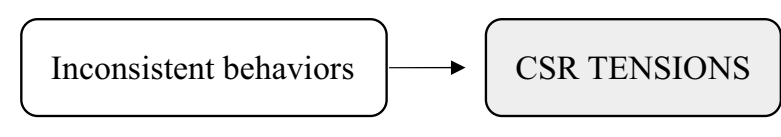

Competing decisionmaking rationales

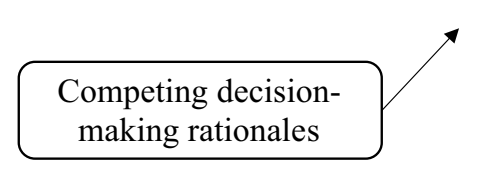

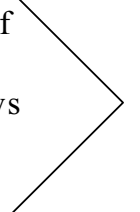

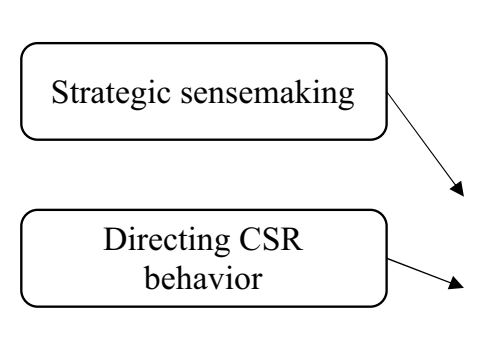

MANAGEMENT

PRACTICES

Fig. 1 Data structure for CSR tensions and management practices 


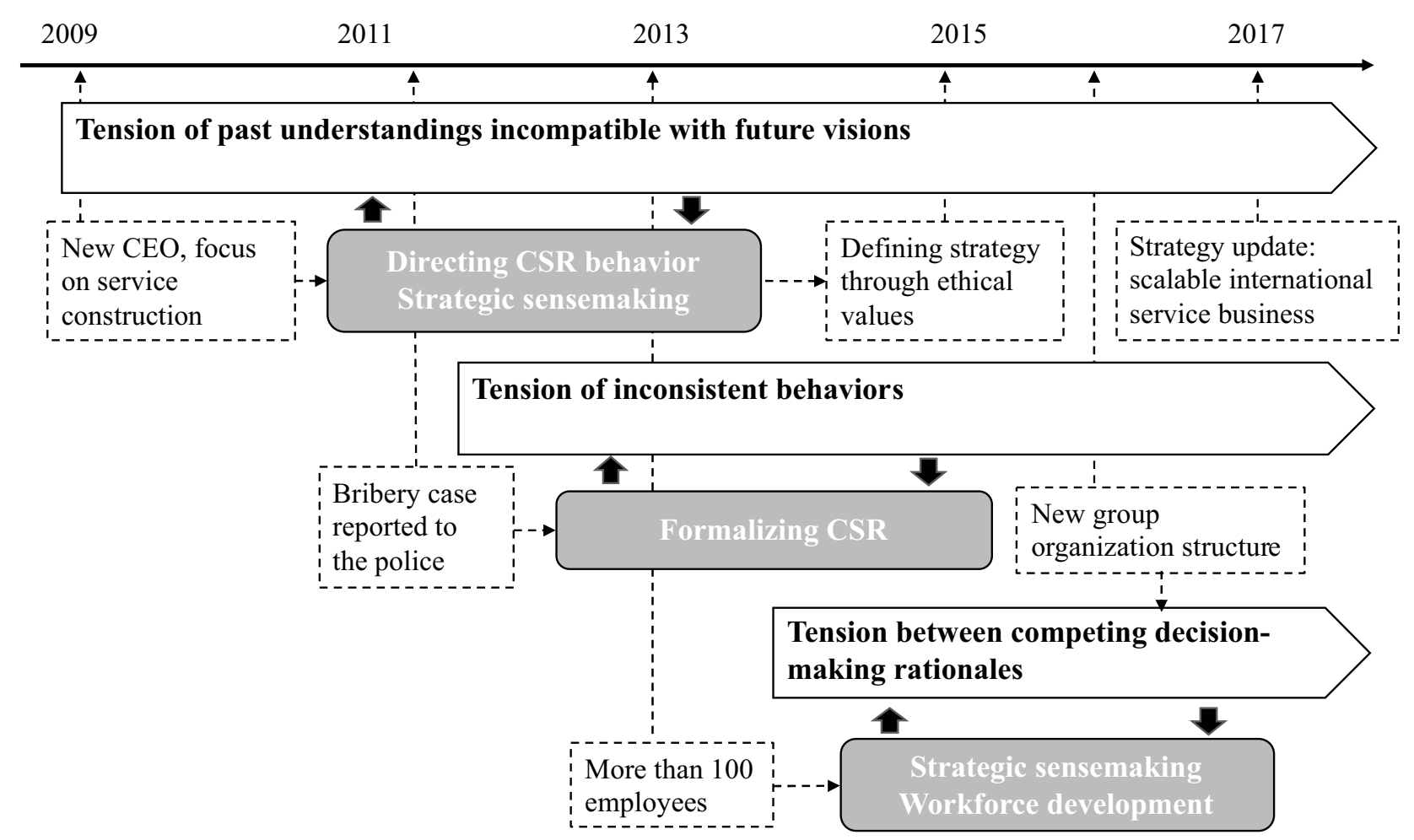

Fig. 2 Timeline of the case-the emergence of CSR tensions and management practices

organization members engaged with the three CSR tensions in specific situations. Using our memos, field notes and participant observations as further guidance, we described how the four management practices had supported individuals and groups to navigate the CSR tensions in specific ways, and how this contributed to strategic CSR integration. In this last step, we compared our emerging observations with recent studies on tension management (e.g., Jarzabkowski et al. 2013; Jarzabkowski and Lê 2016), and used their distinction between active and defensive responses to tensions as basis for discerning and characterizing five approaches to navigating the CSR tensions. Below, we explain how these approaches to navigating CSR tensions shaped the strategic CSR integration process.

\section{Findings: The Emergence and Management of CSR Tensions}

Through data analysis, we identified three types of CSR tensions that challenged the strategic CSR integration process and four sets of management practices that balanced these tensions and supported the embedding of CSR into SmartCo's strategy. Figure 1, along with Tables 3, 4, and 5 , illustrate their empirical grounding.

Our analysis, organized according to the three CSR tensions, explicates how the identified management practices addressed the CSR tensions and supported the integration of CSR into SmartCo's strategy. These tensions, along with the associated management practices and main organizational events, are visualized on the timeline in Fig. 2.

\section{The Tension Between Past Understandings and Future Visions}

\section{Nature of Tension}

The service-focused strategy introduced in 2009 distinguished SmartCo from the traditional approach to construction. The new strategy contrasted several prevailing assumptions about the construction business as a technical engineering operation, which created confusion among organization members over the meaning of "service," and later, over the nature of the company's commitment to ethical values. Referring to the data structure (Fig. 1) and Table 3, the common denominator for these tensions was the incompatibility between past understandings and future visions. Here, the CSR tension stemmed from the cognitive distance between the institutionalized understanding of construction business, on the one hand, and the espoused strategic vision of construction as a responsible service business, on the other. Involving long-standing professional identities, this resembles what Smith et al. (2013) describe as tensions of belonging (see also Smith and Lewis 2011); the tension between past understandings and future visions 
Table 3 Empirical support for management practices associated with the tension between past understandings and future visions

\begin{tabular}{ll}
\hline Second-order theme & Underlying codes \\
\hline $\begin{array}{l}\text { CSR tension: Past understandings incompat- } \\
\text { ible with future visions }\end{array}$ & Inherited industry attitudes contradict values
\end{tabular}

Illustrative quote

ible with future visions

Ethical values lack concrete guidelines

Strategic visions confusing

Management practice: Strategic sensemaking

Communicating values

Explicating business strategy with ethical values

Maintaining internal dialogue and debate on the strategic direction

CEO's personal values, presence
We all have worked elsewhere and have a history, myself included. And the challenge is how to get people to adopt the attitude [...] that we invest in long customer relationships and do not optimize a single project. (EVP, March 6, 2015)

Beautiful sentences are written all over. Should specify what values mean in different contexts. What is transparency at the construction site? Is it different for each contract type? (Participant experiences from ethical training, September 1, 2014)

[A co-worker] said it well that we have been doing this for six years now and nobody still understands why [we advocate] service construction. (HR director, September 22, 2015)

[CEO] and [HR director] especially talk a lot about the values, in every meeting of collective events, the more strategic ones especially, we always look at things through the values (Development manager, June 14, 2017)

Despite all attempts, we don't [have a written strategy].[...] Instead, we try to describe it with this cultural, or... Not with typical strategic elements or with things that create competitive advantage, but through this societal change theme, what we want to accomplish. (Director, housing business, February 4, 2015)

The thing is about interpersonal relationships. When you walk around the office, see people, talk to them [...] Not so much about having logical management processes but about creating communication, look at things together, having a low culture in a way. (CEO, April 24, 2015)

[This] comes back to [the CEO] in many ways, what kind of person he is, how unyielding and uncompromising he is with certain things. Take for example the issues with the black economy or bribery, these reflect [the CEO] a great deal, and how he has managed to infect others with this ethos. (Development manager, subsidiary, May 5, 2015)

Transparency with ethical issues

At the beginning of 2012, we made a request for investigation to the police regarding suspected bribery and fraud in [a construction project]. This was based on an internal investigation. (Annual report of 2012)

Setting example with visible problem resolution
A good example is the alteration cost disagreement with [a major client], in which [the $\mathrm{COO}]$ and [CEO] agreed it with [the client's] top management. I think they have set an example. (Development manager, April 15, 2015) 
made it difficult for organization members to comprehend, endorse and enact the strategic visions that sought to redefine the basis of the company's business.

\section{Management's Response to CSR Tension}

Two management practices were central to balancing the tensions between past understandings and future visions (see Table 3). As the initiator of the strategic change process, the CEO played a pivotal role in directing CSR behavior by promoting the initially customer-oriented and later explicitly ethical business direction by personal example, and clarifying it through communication. Especially in the earlier stages, the CEO's personal impact on the small organization was significant in instilling an open-minded and development-oriented culture in the company. As one informant recollected,

It starts with [the CEO]. [...] He is visible, talks a lot with people, it is infectious. He is a good storyteller, very skilled at it. (CCO, March 11, 2015)

The CEO also set a personal example of transparency and commitment to ethical principles from early on. For instance, in 2012, the CEO learned of bribery in one of the company's projects. This case, which the CEO reported to the police, threatened the company's survival and cast a shadow over the legitimacy of the company's strategic direction. The CEO's transparent handling of the bribery case, both internally and in public, helped to take action against unethical practices. It was, therefore, instrumental in accentuating the ethical dimension of SmartCo's strategy, and in setting a clear example within the company for ethical integrity and behavior.

Also, the CEO and top management engaged many members of the organization in strategic sensemaking. As an essential part of this management practice, SmartCo cultivated open dialogue and critical debate on strategy, which helped the management to bridge the gap between understandings inherited from the construction industry and the company's distinctive and continually evolving strategic vision. The open dialogue, coupled with the ambiguity of the core strategy attributes, such as "service construction" and the core values of "trust, transparency, and responsibility," maintained the strategic visions and statements in an ever-provisional state that invited organization members to interpret them in their own contexts. This, for example, allowed the construction project personnel to make sense of customer centricity and ethical values through the new collaborative practices introduced to the projects.

Among top management, this cultivated reflexivity and paradoxical thinking (see Hahn et al. 2014, 2016) by giving attention to the complex issues and targets in discussions without imposing a single uniform "truth" that could have easily suppressed the diversity of relevant viewpoints. This was evident in the heated debates among top management over, for example, the balance between the society-improving visions and demands of current construction operations, and between continuing growth and the need for stability and clarity. Rather than stifling this debate, the CEO purposively maintained a dialogue despite the conflict to move forward with the strategy:

I was in the executive group yesterday, and I said that this means you don't have to like me; you can disagree, but we have to find an agreement together. If we let go of the diversity, if we would agree, it would be easy [...], but we need it to disagree and then to find agreement. (CEO, April 24, 2015)

\section{CSR Integration Through Organization-Wide Recognition of Tensions}

Strategic sensemaking and directing CSR behavior supported organization members in linking their past understandings about construction with the future visions of the company in two ways. First, these management practices increased the legitimacy and salience of ethical values as an integral part of business strategy by integrating the ethical values and society-improving visions into the formal business strategy and mission. For example, the annual reports show how the narrative of the business strategy shifted from "service model" and "customer orientation" (AnnRep 2011) to highlight the values of trust, transparency, reliability, and responsibility (AnnRep 2013) as crucial concepts in explaining the nature and content of the business strategy. Instead of strictly separating CSR from business strategy, both the formal strategy statements and internal materials framed the ethical values as crucial elements in the successful implementation and growth of the service-focused construction business (Summary of internal workshops, September 15, 2017).

Second, the management practices cultivated recognition of the tension itself as a more permanent part of the company. Here, we use recognition to refer to the actors' acknowledgment of the competing goals and their willingness to live with the ensuing tensions while giving both business and ethical sides of the matter an appropriate consideration. This constitutes an active response to the CSR tension; it afforded a longer-term resolution by accepting the tension as a reasonable condition of organizational life (Jarzabkowski et al. 2013; Lewis 2000). Communicated by top management and enacted through their decisions, recognition took place at the organizational level in legitimizing the ethical values and incorporating ethical elements into strategic decisions. As top and middle managers were aware and tolerant of the tensions between past understandings and 
future visions, they saw the navigation of such tensions as part and parcel of realizing the company's ambitious visions. Recruitment, for example, entailed a balancing act between deep technical and business expertise ('past') and capability for innovative and ethical practices ('future'):

We need experienced individuals [...] to undertake larger projects; we need their expertise and experience. But we have also hired lots of younger people because they are capable of learning. [...] The problem is how to give these young people opportunities for growth while avoiding the [transfer of] bad habits. (COO, March 11, 2015)

The acceptance of ethical values as a legitimate basis of business strategy also translated into concrete strategic actions, such as investments into the pipe renovation (2011) and housing business (2014) subsidiaries. These units adopted the ethical values and society-improving mission as guiding principles in the development of new solutions to customers. Also, increasing attention was devoted to new contract types and collaborative practices in construction projects as manifestations of this strategy, allowing operative-level employees to make sense of the strategy in the context of their work.

\section{The Tension of Inconsistent Behaviors}

\section{Nature of Tension}

As the new strategy, based on ethical values, gradually gained acceptance, the second set of CSR tensions emerged around the implementation of the ethical values in day-to-day activities. These tensions of inconsistent behaviors derived from an internal variance in adherence to, and enactment of, the ethical values. Especially in construction projects, the reliance on competent project managers meant that not all project teams adhered equally to the ethical values but instead perpetuated the industry's business-focused practices (for empirical grounding, see Table 4). As such, the inconsistent behaviors resemble the tensions of level discussed by Hahn et al. (2015) as different levels and parts of the organization disagreed on ethical values and enacted them differently, without collective synchronicity in working toward a shared goal.

Table 4 Empirical support for management practices associated with the tension of inconsistent behaviors

\begin{tabular}{ll}
\hline Second-order theme & Underlying codes \\
\hline CSR tension: Inconsistent behaviors & $\begin{array}{l}\text { Variation in compliance between individu- } \\
\text { als, projects }\end{array}$
\end{tabular}
Illustrative quote

\section{Management cuts corners}

CSR behaviors lag spoken values

Management practice: Formalizing CSR Introducing formal ethical code

Ethical principles as part of job contracts

New KPIs with stakeholder focus

Systematization of processes and contracts
There are clear differences between construction sites and project managers, and I've heard it from others too; they say the vibes are different. (Development manager, April 24, 2015)

I think this is not about having management who do not believe in our values and want to act accordingly, but it is the speed [of change] that makes them cut corners. (HR director, November 6, 2017)

We have good basis for our values and everyone tries to promote them, that's clear. But [...] the starting level is so low that even if we talk about transparency and caring and support, it is still in its infancy. (Manager, IT development, January 27, 2017)

High ethical principles are an important part of SmartCo's operations and support the dependability, productivity, image and good internal atmosphere. (Foreword to the company's "deck of ethics cards" August, 2017)

Every time a new employee is hired, they sign the code of ethics as a part of the contract of employment. (Development manager, April 24, 2015)

For example, we have this renovation work [...] in which a significant portion of our fee is connected [...] to maintaining the users' customer streams. (CCO, March 11, 2015)

We have spent a lot of effort to describe our operations. We have the building movement themes, and certain strategic targets under these main themes.[...] And these are broken down to the individual level, so that everyone can see how their day-to-day work is related to the company's goals. (Director, construction operations, February 14, 2017) 


\section{Management's Response to CSR Tension}

Inconsistent behaviors were addressed through various means of formalizing CSR to establish a common baseline for ethical conduct (see Table 4). A formal code of ethics was introduced in the wake of the bribery case in 2012 to prevent future wrongdoing in construction projects, and to provide a clear set of standard rules for ethical behavior. As an example, SmartCo gave a deck of ethics cards to every employee, explaining the company's ethical principles and discussing specific cases, such as perquisite positions, business gifts, and equality. The company's ethical principles were written into each labor contract, and each new employee had to agree to them before signing the contract. Each employee was also required to complete regular ethical training on topics such as organized crime in construction, transparency in operations, and gender equality.

In business operations, SmartCo formalized CSR by introducing non-financial performance indicators to reward personnel for their efforts to induce greater collaboration and transparency among project stakeholders. For example, in a renovation project, the fees were tied to the customer experience of the project. The top management also set an example in resolving conflicts in construction projects with priority to non-financial goals, which accentuated the importance of the ethical basis of business and set a benchmark for employees to make similar choices. Finally, the top management increased systematic supervision of construction projects to gain better control over both the business and ethical aspects of project performance. The following statement discusses how regular meetings and standard reporting, as an example, guided project managers to follow the company's principles:

We, too, have a lot of that mindset where [project managers] don't want to disclose all of the details [...] it is difficult to change people in that sense. But you can build your operations and systems in such a way as to force everyone to disclose everything as openly as possible. (COO, March 11, 2015)

\section{CSR Integration Through Formal Policy and Evasion of CSR Tensions}

The formalization of CSR created an organization-wide policy, which clarified the expected ethical standards to the personnel. Thus, it reined in the most blatant forms of ethical misconduct by specifying clear rules on acceptable and forbidden behaviors. Also, it established proper channels for reporting observed issues. The ethical code concretized the meaning of ethical conduct for individuals and placed it explicitly on the organization-level agenda in two ways: First, it delineated a manageable set of ethical issues for the personnel to target. Second, it stipulated the "minimum standard" for ethical behavior in these issues, thus weeding out the most egregious violations of the company's values. Hence, it became an instruction manual of sorts, as explained by an informant:

We have given the ethical deck of cards to everyone, done the training, and signed job contracts. People understand our values and that there are no exceptions. [...] it shouldn't be a surprise that something is forbidden. Even if it was legal. (Development manager, April 24, 2015)

Such formalization, however, steered toward the organizational-level evasion of the tension of inconsistent behaviors. As the ethical code rendered ethical behavior a relevant concern only in a small number of issues domains, it allowed members to continue to prioritize technical and financial aspects of the operations without having to confront the CSR tension in many areas of their work. In particular, the issues of the black economy were foregrounded at SmartCo, with clear rules on acceptable and prohibited behavior. At the same time, decisions related to project scheduling, resourcing, or stakeholder interaction, for instance, received much less systematic ethical consideration (participant observation, September 2017). As one project manager commented,

the values and ethical principles direct our actions, but it is a positive thing that each [project manager] can make a construction site their own, so long as the common principles are OK. (Field notes, internal workshop, August 31, 2017)

As the quote implies, prioritizing ethical values on issues falling outside the scope of the ethical code was left largely to each individual's discretion. Evasion thus constitutes a defensive response; it provided a partial relief on organization members in dealing with complex pressures, but did so by suppressing the ethical side rather than embracing it as a critical element in day-to-day decisions (Jarzabkowski et al. 2013). This defensive response allowed SmartCo to work around the CSR tension by maintaining the salience of ethical themes, on specific issues, while continuing to prioritize business targets on others.

\section{The Tension Between Competing Decision-Making Rationales}

\section{Nature of Tension}

In parallel to the two CSR tensions mentioned above, the rapid growth and internal structuring of SmartCo triggered the third set of tensions, which we characterize as tensions of competing decision-making rationales (see Table 5 for empirical grounding). This type of tension foregrounds 
Table 5 Empirical support for management practices associated with the tension of competing decision-making rationales

\begin{tabular}{|c|c|c|}
\hline Second-order theme & Underlying codes & Illustrative quote \\
\hline \multirow[t]{4}{*}{$\begin{array}{l}\text { CSR tension: Com- } \\
\text { peting decision- } \\
\text { making rationales }\end{array}$} & Performance guidance constricts the realization of visions & $\begin{array}{l}\text { Many expressed the feeling that service strategy and freedom } \\
\text { to develop only materialize in speech while performance } \\
\text { guidance constricts good ideas and visions into the same old } \\
\text { thing. (Internal summary of strategy workshops, November } \\
\text { 2017) }\end{array}$ \\
\hline & Tolerating unethical practices to protect cash flows & $\begin{array}{l}\text { The gap between strategy and doing: Old MOs are accepted, } \\
\text { particularly in construction projects, because that is where } \\
\text { the money is made (e.g., exploiting sub-contracts far from } \\
\text { collaborative relationships). (Field notes, August 28, 2017) }\end{array}$ \\
\hline & Diverging strategic investment priorities & $\begin{array}{l}\text { Guess how the people feel who generate the cashflow and } \\
\text { know. It }[\ldots] \text { If they start to feel that they are not getting } \\
\text { bonuses because the revenue is eaten up by the new stuff. } \\
\text { (HR director, November } 6,2017 \text { ) }\end{array}$ \\
\hline & Gap between projects and HQ & $\begin{array}{l}\text { Some pointed out that differences between headquarters and } \\
\text { project teams arise from different goals and practices. Others } \\
\text { indicated that mental differences are more significant and } \\
\text { that not everything done at the headquarters is seen in posi- } \\
\text { tive light. (Field notes, October 18, 2018) }\end{array}$ \\
\hline \multirow[t]{4}{*}{$\begin{array}{l}\text { Management prac- } \\
\text { tice: Developing } \\
\text { workforce }\end{array}$} & Recruitment based on employees' compatible values & $\begin{array}{l}\text { Most interviewees answer my question 'Why SmartCo?' by } \\
\text { saying that it is our message that speaks to them, that they } \\
\text { want to come and change things with us, do things differ- } \\
\text { ently. (COO, March 11, 2015) }\end{array}$ \\
\hline & Compulsory ethical training & $\begin{array}{l}\text { And we organize ethical training once a year.[...] For example, } \\
\text { last summer, we had a prosecutor explain when the criteria } \\
\text { are met for him to prosecute. (COO, March } 11,2015)\end{array}$ \\
\hline & Organization-wide events with CSR focus & $\begin{array}{l}\text { It was nicely expressed in our development day when [the } \\
\text { CEO] gave a } 15 \text {-min presentation on our values, why they } \\
\text { matter and talked a lot about trust. (HR director, November } \\
6,2017 \text { ) }\end{array}$ \\
\hline & Endorsement for learning, innovation & $\begin{array}{l}\text { The absolute strength of SmartCo, something that's deeply } \\
\text { ingrained in the culture, is this almost infinite enthusiasm } \\
\text { and open-mindedness, you can try out and advocate just } \\
\text { about anything, which is likely the reason that some of the } \\
\text { ideas have turned into successes. (Head of strategy develop- } \\
\text { ment, March 3, 2017) }\end{array}$ \\
\hline
\end{tabular}

the differences between the technical and financial criteria for managing construction projects, on the one hand, and the customer-centric and ethically responsible view of the business advocated mainly by the top management and select business units, on the other. Although the tensions among competing decision-making rationales was present throughout the study period, given the spatial (and cognitive) distance between the construction sites and the headquarters, it became increasingly salient in the last three to four years when the company's personnel grew well into the triple digits. While in earlier stages the proximity of the CEO and other executives helped navigate the ensuing tensions in the CSR integration process (see above, also Weaver et al. 1999b), the growing middle management, increasing reliance on formal control systems, and the widening gulf between the business units undermined collective commitment to common values and targets.
As such, the tensions among competing decision-making rationales resemble what Smith and Lewis (2011) describe as the tensions of performing (see also Ozanne et al. 2016; Smith et al. 2013): the organizational sub-units began to interpret and prioritize the ethical values differently in their hierarchy of goals and strategies. Also, the revised business strategy, introduced in 2017, separated the company-level development targets, incorporating the ethical values and society-changing mission, from the efficiency-focused goals of the construction business unit. This discrepancy increasingly undermined SmartCo's strategic commitment to CSR.

\section{Management's Response to CSR Tension}

In response to the tensions associated with competing decision-making rationales, the management intensified the use of ethical values and society-improving mission as a central part of strategic sensemaking, helping different business 
units to link their efforts with the same unifying purpose (for empirical support, see Table 3). Furthermore, from 2014, the management started to organize company-wide events once or twice a year to communicate the strategy more systematically. One of these events focused on organizational culture to reinforce the ethical basis and collective direction for the rapidly growing company. For example, the top management organized a company-wide series of strategy workshops in 2017 to clarify the role of each business unit in the bigger picture.

In parallel to the internal sensemaking, the ethical values and mission became more central to external communications, with the CEO making high-profile appearances in the mainstream media calling for more socially responsible practices in the construction industry. These internal and external events with converging storylines strengthened the credibility of the ethical business strategy. They provided a personally meaningful basis for members to commit to the strategic visions that emphasize ethical values and responsible practices as a means to achieve societal change. Echoing the sentiments of many employees, a project manager explained how

the values speak to us on a personal level, and we live by them. [...] Our culture is good for us as people; it is engaging, offers opportunities for personal development. (Field notes, internal workshop, August 31, 2017)

Furthermore, commitment to the ethical strategy was reinforced through concerted efforts to develop the workforce (see Table 5). First, it involved an increasingly selective recruitment of new employees, emphasizing the compatibility of their personal values with those of the company. Although exceptions were made in the construction business due to its rapid growth and high demand for technical expertise (furthering all three types of CSR tensions), the positive external image of the company enabled SmartCo to cherrypick employees that were interested in society-improving innovation. Furthermore, workforce development involved ethical training to deepen the awareness of ethical questions within the organization.

\section{CSR Integration Through Situated Adjustment Based on Organizational Identity}

These management practices reinforced members' awareness of, and commitment to, ethical values. Besides strengthening the grounding of formal strategy in ethical values, the management practices deepened the way in which the members of the organization conceived of themselves as an organization - that is, their organizational identity (Albert and Whetten 1985). Indeed, the ethical values and society-improving mission were frequently mentioned as the central and distinctive features of SmartCo, which for many, offered a personally meaningful basis for withstanding the tensions and working toward the company's visions.

I think the values we have, what [the CEO] talks about, trust and these things are essential, and that we start with the customer's needs and goals and strive to find the future users the kind of buildings they need. [...] Our way of thinking is respectable. It supports what I want as a person, what kind of values I have. (Foreman, April 28, 2015)

This statement reflects how the organizational identity, based on ethical values, transcended business unit boundaries and allowed organization members to see themselves as part of the organization's mission despite the somewhat diverging targets and decision-making rationales. Concerning the tension between competing decision-making rationales, the organizational identity supported individuals in making situated adjustments to accommodate, at the action level, both the ethical and business aspects when dealing with the complex targets imposed on their work. Hence, it was an active response based on the acceptance of both the financial and ethical aspects as essential for the company's longterm success (Jarzabkowski et al. 2013). For example, the identity-defining values offered individuals critical concepts with which to put the day-to-day challenges into perspective and to orient their efforts toward larger goals, as indicated in the following interview segment:

I understand [our vision] to mean that we are building a smarter society, in very concrete terms. [...] we are breaking the existing myths and practices in the construction industry. I believe that SmartCo is a construction company for the people, and with my effort, I too try to get us past the egoistic culture, to change things through collaboration, even with our competitors. (IT development manager, January 27, 2017)

\section{Navigating Inconsistent Support Through Confrontation and Regression}

At the same time, the ongoing separation of business units and their strategic objectives undermined individuals' ability to reconcile ethical with business goals in their work. As discussed in the context of inconsistent behaviors, the management offered little support for individuals in navigating the multiple decision-making rationales outside the scope of the ethical code. In some cases, it even set a contrarian example by tolerating unethical behaviors to secure profits in construction projects despite advocating ethical values in organizational-level strategic sensemaking. 
This placed significant pressure on individuals to advocate ethical values at the action level while pursuing their business goals. Although the organizational identity provided a backbone for ethical deliberation and adjustment between the dual targets, many employees experienced dissonance between espoused values and actual priorities, and felt powerless to advocate the ethical values under the financial pressures and busy schedules of their daily work:

Participants' sentiment: In principle, we are encouraged to be self-directive, supported to develop ourselves, but often the frame [of day-to-day targets] is so tight that we end up into a forced compromise where only the frame matters. (Summary of internal workshops, September 15, 2017)

This animation of the CSR tension was evident, for example, in informal discussions voicing complaints about situations in which the efforts to advocate the values were diluted or downright blocked by the management. This internal contradiction forced individuals to respond to CSR tensions in one of two ways in their day-to-day actions. First, some individuals were more centrally positioned and adept at advocating the ethical values by directly confronting the tension by bringing it under explicit discussion, even when it heated up the situation (Lewis 2000). In one instance, the HR team implemented measures to support employee wellbeing, including a system for worktime monitoring, which clashed with the prevalent exploitation of unpaid overtime. While some project managers accepted the new HR policy for tracking work time, seeing it as compatible with the company's values and beneficial over the longer term, the policy also induced clashes with project managers and business unit management over the detrimental impact of the policy on profits (participant observation, December 2017).

In contrast, many individuals, especially in operative positions, were forced to ignore the ethical values and regress (Lewis 2000) to focus on financial targets alone to survive their heavy workload (field notes, informal discussion, September 1, 2017). Indeed, the disconnect between espoused support for self-directive work as per the company's values, and the reality of strict day-to-day targets, forced compromises on everything but the short-term business targets, giving employees little option to promote ethical values, especially as the management did not give a clear signal that the ethical aspirations mattered beyond the scope of the ethical code. For example, a new foreman, who had accepted the company's values wholeheartedly, identified an ethical issue in his current project and brought his concern to the project manager in an attempt to rectify it. When the project manager rejected this effort, citing the functioning and profitability of the construction site, the foreman took the issue to the business unit management. However, the management then disciplined the foreman for escalating the matter, although later, a top manager involved in the case admitted that the foreman had been correct to demand more ethical behavior (Field notes, informal discussion, October $5,2018)$.

\section{Strategic CSR Integration Through Navigating CSR Tensions}

In summary, the management practices adopted in response to the three types of CSR tensions allowed SmartCo to navigate the CSR tensions and thus contributed to strategic CSR integration. We use the term navigation to highlight the need for ongoing effort in apprehending and addressing the CSR tensions that arise during the strategic CSR integration process and elude permanent resolution (Jay 2013). As we summarize in Table 6 and discuss below, SmartCo's approach to navigating CSR tensions (bolded) extended, but also to some extent undermined, organization-wide commitment to CSR.

Our findings highlight the importance of navigating CSR tensions simultaneously at the organizational and action levels (see also Hengst et al. 2020). Organizationallevel responses relate to the organization's strategic commitment to CSR and its organization-wide efforts, including formal policies and governance, which set the tone for apprehending and addressing the CSR tensions. Actionlevel responses, in turn, pertain to the individuals' and teams' situated reactions to the CSR tensions that confront them in their daily work and influence the degree to which CSR is enacted in the day-to-day actions. The findings reveal how SmartCo succeeded in cultivating organizational-level recognition of the CSR tensions, which introduced and sustained CSR as an integral part of business strategy. It also created an organization-wide policy for ethical behavior. However, inadequate support for navigating tensions at the action level, especially in construction projects, contributed to perpetuating CSR tensions, prioritizing business over ethical targets, and thus inhibiting the integration of CSR into day-to-day actions across the organization.

The findings also distinguish between active and defensive responses to tensions (Lewis 2000; Jarzabkowski et al. 2013), proposing the active response to be necessary for advancing strategic CSR integration as they allow organizations to deal constructively with the CSR tensions with an eye on maintaining a long-term balance. For example, top management's strategic sensemaking and personal direction-setting allowed SmartCo to cultivate organization-wide acceptance of the ethical business strategy by recognizing the tensions between past understandings and future visions. Similarly, strategic sensemaking and workforce development shaped organizational identity around ethical values, supporting individuals to adjust 
their behaviors between competing decision-making rationales. Conversely, defensive responses to CSR tensions provided only short-term relief from the tensions by compromising on some of the CSR aspects in the business practice. For example, the formalization of CSR through an organization-wide ethical code rendered CSR a legitimate concern only in a few issue domains. Although this simplified the content of CSR for organization members, it also supported the defensive evasion of CSR tensions, which left the members of the organization to their own devices in dealing with many of the CSR tensions they experienced at the action level.

As a result, the ethical values that were salient in communications regarding business strategy and future visions became increasingly divorced from members' day-to-day experiences (Summary of internal workshops, September 15, 2017). As elaborated in the following quote, this amplified CSR tensions and eroded the members' commitment to the ethical business strategy:

We talk about [the values] more than others, but you also hear more about there being a significant bulls**t gap. [A colleague] brought up this a few weeks ago, that we get a lot of feedback that the management does not act in accordance with the values. [...] And this is not an issue of the management not believing in our values, but the speed is so high at the moment that it forces [us] to take shortcuts, which makes the values invisible [in our work]. (HR director, November 6, 2017)

That is, misalignment in navigating CSR tensions, both between organizational and action levels and between business units, stalled and threatened to reverse strategic CSR integration at SmartCo. Thus, our findings suggest that alignment in navigating CSR tensions across the organization is crucial for maintaining CSR on the strategic agenda over time.

\section{Discussion and Contributions}

Integrating CSR into the strategy and core business activities of a for-profit company is laden with tensions stemming from the contradictions between business and CSR. Our findings from a construction company revealed several management practices that allowed the company to cope with CSR tensions. The findings emphasize the essential role of active navigation of CSR tensions, and alignment in navigating the tensions between organizational and action levels. 


\section{Implications for Research}

Our findings make three main contributions to the CSR literature. First, we contribute to the CSR development literature by foregrounding the CSR tensions and the means to navigate them as a central yet previously overlooked element in the strategic CSR integration process. Prior research on CSR development has focused on describing the stages of CSR integration (e.g., Maon et al. 2010; Mirvis and Googins 2006; Reidenbach and Robin 1991), the associated management challenges (Rossouw and van Vuuren 2003), and the systematic design and implementation of CSR programs for organizations (e.g., Ingham and Havard 2017; Maon et al. 2009). Extending this work, we shed new light on how management can improve the ability of the organization to navigate the CSR tensions that inevitably arise when making the transition from a dismissive or peripheral to an integrated CSR approach (Aguinis and Glavas 2013; Weaver et al. 1999b). Our findings portray strategic CSR integration as an ongoing process of navigating CSR tensions that remains, to varying forms and degrees, part of the life of the organization. Correspondingly, the advanced stages of CSR integration are characterized less by "the seamless integration of ethics in corporate purpose, strategy and operations" (Rossouw and van Vuuren 2003), and more by persistent internal tensions and growing efforts to rein them in without losing sight of either the business or CSR targets.

Second, our findings contribute to the CSR development literature by improving the current understanding of the precise ways in which navigating CSR tensions influences the process of strategic CSR integration. Here, we draw on two distinctions-between the organizational and action levels as the locus of navigating tensions (Hengst et al. 2020), and between active and defensive responses to tensions (Jarzabkowski et al. 2013). Our findings show how CSR development depends on the navigation of CSR tensions at both the organizational and action levels; building acceptance of a responsible business strategy at the organizational-level supports, but must also couple with, the navigation of CSR tensions at the action level. Furthermore, alignment between the levels in navigating tensions is essential for CSR integration, with emphasis on active responses. Whereas defensive responses can stall the CSR integration process, for example, by prioritizing business targets over CSR, the active navigation of CSR tensions builds a longer-term balance between business and CSR by accepting and working through the tension. Alignment refers here to the compatibility and complementarity of responses across organizational levels, but not to complete uniformity in responses to tensions across the organization. In the context of CSR tensions, it is necessary to tolerate discrepancies between formal and informal responses
(Crilly et al. 2012) and leverage conflicting management practices (Scherer et al. 2013) to navigate situational contingencies constructively (Jarzabkowski et al. 2013). In this spirit, our findings add a new layer to studies that call for internal consistency between business and CSR within the organization (e.g., Basu and Palazzo 2008; Yuan et al. 2011).

Third, our findings shed new light on the integrative view of CSR, and especially the insights it brings to the management of CSR tensions as an unavoidable and inherent part of strategic CSR integration (e.g., Gao and Bansal 2013; Hahn et al. 2015). Whereas this literature has remained largely conceptual (Van der Byl and Slawinski 2015), drawing on the ideal type tensions and solution mechanisms rooted in the paradox literature (e.g., Hahn et al. 2018; Smith and Lewis 2011), our study offers new, empirically grounded insights into the management of tensions in the strategic CSR integration process. Specifically, we shed new light on how organizations navigate CSR tensions, and explicate the role of management's interventions in supporting and obstructing the active navigation of CSR tensions. Thus, our findings open doors to more nuanced and multifaceted accounts of managing CSR tensions. For example, we expand the studies of the individual- and organizationallevel capabilities for balancing tensions (e.g., Hahn et al. 2016; Ivory and Brooks 2018; Vallaster et al. 2019) by illustrating how such capabilities (e.g., strategic sensitivity, collective commitment, the climate of reflexivity)—viewed here through the lens of management practices-reinforce the ability of the organization to sustain its focus on both CSR and business targets.

In addition, this paper engages with studies that adopt a practice perspective to adopt a practice perspective to the management of paradoxical tensions. As some of the CSR tensions observed in our study had paradoxical elements (e.g., Lewis 2000), our analysis complements the practicefocused line of work by exploring how an organization can navigate paradoxical tensions at the organizational and action levels (e.g., Lüscher and Lewis 2008; Smith and Lewis 2011). Jarzabkowski et al. (2013) have shown that responding to a paradox is a dynamic and ongoing process involving different types of responses evoked by organization members as part of their work. Through elements such as humor (Jarzabkowski and Lê 2016) or "both/and" thinking (Lüscher and Lewis 2008), individuals can work constructively with the paradoxes and transform them to support innovative solutions (Beech et al. 2004; Jay 2013)—including those that integrate business and sustainability targets (Hengst et al. 2020). Our findings advance this research by translating its insights to the CSR context and making them applicable to questions about CSR integration. Also, our study highlights the impact of management interventions 
and organization structure on the navigation of CSR tensions at different organizational levels.

\section{Managerial Implications}

From a managerial standpoint, we follow Porter and Kramer (2006, 2011) in advocating strategic CSR integration as the pathway through which companies can credibly respond to the growing criticism of their lack of social and environmental responsibility. However, this is not a straightforward task, given the persistence of CSR tensions. Our findings offer guidance for managing strategic CSR integration in relation to two managerial challenges. The first challenge is to cultivate the acceptance of CSR as an integral part of business strategy. We show how this acceptance depends on strategic sensemaking that integrates CSR into the company's long-term visions and definition of competitive advantage. In addition to top management communication, the sensemaking process should enlist organization members in debating the company's direction and couple with the personal example of top management in prioritizing nonfinancial goals. Selective recruitment and systematic training in alignment with the company's values provide suitable means for managing tensions in this regard.

The second challenge is the avoidance of mission drift in the face of recurring business challenges and persistent CSR tensions. This requires management to support employees in advocating CSR agendas at the operative level. While shared policies help clarify the enactment of CSR, support is needed for employees to make choices that prioritize CSR, with emphasis on removing obstacles such as contradicting reward systems. Management must also take care to balance the demands placed on employees concerning operational and developmental targets because fatigue and constant pressure limit employees' ability to remain attentive and reflexive toward business and CSR goals simultaneously. Finally, the management should regularly reinvigorate the company's commitment to CSR, for example, through ethical training and the inclusion of CSR as a topic in companywide events. This keeps CSR at the forefront of employees' attention and signals that the management cares, especially when management decisions are consistent with the policies that it espouses.

\section{Limitations and Future Research}

Certain characteristics of our case bring a distinctive flavor to our study and influence the generalizability of our findings. In the small but rapidly growing company, the CEO wielded significant influence over the organization's CSR orientation and identity reformation, especially early on in the CSR integration process. Although we believe that the same management practices and underlying approaches to navigating CSR tensions are relevant to larger organizations pursuing strategic CSR integration, future research is needed to explore the navigation of CSR tensions in established organizations that are likely to take a more systematic approach to initiating the "cultural" change that grounds strategic CSR integration (e.g., Ingham and Havard 2017).

Also, the construction industry is characteristically local and capital-intensive, and CSR has not played an essential role in its reputation. This context made it easy for SmartCo to differentiate its strategic advantage and organizational identity by underscoring ethical values, something which may not be as easy for companies in industries with higher ethical standards and requirements for CSR. Thus, industries that are more sensitive to CSR issues may exhibit different types of CSR tensions and call for companies to respond to stakeholder demands differently from our case context. In addition, the spatially dispersed organization of construction companies poses unique challenges for implementing CSR at the operative level. More research is needed to understand the distinct demands and implementation pathways of CSR across industries.

Methodology-wise, our findings are limited by our largely retrospective analysis of the navigation of CSR tensions. While the documents and retrospective interviews enabled us to develop a coherent understanding of CSR tensions and CSR integration outcomes over a nine-year period, we encourage future research to adopt an ethnographic approach to investigate more deeply how individuals and groups navigate CSR tensions in real-time. Furthermore, such a research approach enables a closer analysis of how the different tactics to navigate tensions intersect over organizational change processes, and co-evolve with the CSR tensions. An ethnographic approach would also enable future work to focus on the transitions between CSR development stages (Maon et al. 2010), and investigate the factors that either maintain or resolve internal discrepancies among different parts of the organization in integrating CSR into business practices (Mirvis and Googins 2006).

Finally, our work encourages future research to bring the notions of strategy and CSR under closer scrutiny (see also Brooks 2005). Following the practice perspective adopted in the study of paradoxical tensions (e.g., Jarzabkowski et al. 2013), we view strategy and CSR not as something an organization has, but as something it does through its activities in the formulation and implementation of its strategy (Vaara and Whittington 2012). This perspective draws attention to the discursive and material practices through which individuals and groups construct specific notions of CSR and strategy (e.g., Gond et al. 2018). Hence future research is needed to inform us about the ways in which organizational decision-makers relate business and CSR, both discursively 
and practically, as well as how this influences-and is influenced by-the navigation of CSR tensions within the organization.

Acknowledgements Open access funding provided by Aalto University.

\section{Compliance with Ethical Standards}

Conflict of interest The first author declares that he/she has no conflict of interest. The second author declares that he/she has no conflict of interest. During the data collection phase, the third author was employed by the company studied in this paper.

Ethical Approval This article does not contain any studies performed by the authors with human participants or animals.

Open Access This article is licensed under a Creative Commons Attribution 4.0 International License, which permits use, sharing, adaptation, distribution and reproduction in any medium or format, as long as you give appropriate credit to the original author(s) and the source, provide a link to the Creative Commons licence, and indicate if changes were made. The images or other third party material in this article are included in the article's Creative Commons licence, unless indicated otherwise in a credit line to the material. If material is not included in the article's Creative Commons licence and your intended use is not permitted by statutory regulation or exceeds the permitted use, you will need to obtain permission directly from the copyright holder. To view a copy of this licence, visit http://creativecommons .org/licenses/by/4.0/.

\section{Appendix: Positions and Roles of Interviewees}

\begin{tabular}{|c|c|c|}
\hline $\begin{array}{l}\text { Organizational posi- } \\
\text { tion }\end{array}$ & $\begin{array}{l}\text { Round } 1 \text { (Duration, } \\
\text { in minutes) }\end{array}$ & $\begin{array}{l}\text { Round } 2 \text { (Duration, in } \\
\text { minutes) }\end{array}$ \\
\hline Top management & $\begin{array}{l}\text { CEO }(47) \\
\text { EVP }(75) \\
\text { HR director } \\
\quad(104+87+86) \\
\text { CCO }(75) \\
\text { CTO }(75) \\
\text { COO }(84)\end{array}$ & $\begin{array}{l}\text { Manager, strategy } \\
\text { development } \\
(63+77+54) \\
\text { HR director }(96) \\
\text { CTO }(125)\end{array}$ \\
\hline $\begin{array}{l}\text { Construction busi- } \\
\text { ness }\end{array}$ & $\begin{array}{l}\text { Development man- } \\
\text { ager }(80+82) \\
\text { Project manager (60) } \\
\text { Manager, alliance } \\
\text { projects (78) } \\
\text { Foreman (48) }\end{array}$ & $\begin{array}{l}\text { Director, business unit } \\
\quad(44) \\
\text { Development manager } \\
\quad(94) \\
\text { IT development man- } \\
\text { ager (53) }\end{array}$ \\
\hline Pipe renovation & $\begin{array}{l}\text { CEO (78) } \\
\text { Development man- } \\
\text { ager (82) }\end{array}$ & N/A \\
\hline Project consultation & $\begin{array}{l}\text { Director, business } \\
\text { unit (98) }\end{array}$ & $\begin{array}{l}\text { Director, business unit } \\
\text { (59) }\end{array}$ \\
\hline Housing business & $\begin{array}{l}\text { Director, business } \\
\text { unit (72) }\end{array}$ & $\begin{array}{l}\text { Director, housing busi- } \\
\text { ness development } \\
\text { (72) }\end{array}$ \\
\hline
\end{tabular}

\begin{tabular}{lll}
\hline $\begin{array}{l}\text { Organizational posi- } \\
\text { tion }\end{array}$ & $\begin{array}{l}\text { Round 1 (Duration, } \\
\text { in minutes) }\end{array}$ & $\begin{array}{l}\text { Round 2 (Duration, in } \\
\text { minutes) }\end{array}$ \\
\hline Internal ventures & N/A & $\begin{array}{l}\text { Director, business unit } \\
(47) \\
\text { Director, IT develop- } \\
\text { ment (56) } \\
\text { Managers of } \\
\text { internal ventures } \\
\end{array}$ \\
& & $\begin{array}{l}55+60+83) \\
15 \text { interviews, } 17 \mathrm{~h} \\
\end{array}$ \\
Total & 18 min \\
\hline
\end{tabular}

\section{References}

Adnan, H., Hashim, N., Mohd, N., Yusuwan, \& Ahmad, N. (2012). Ethical issues in the construction industry: Contractor's perspective. Procedia-Social and Behavioral Sciences, 35, 719-727.

Aguinis, H., \& Glavas, A. (2013). Embedded versus peripheral corporate social responsibility: Psychological foundations. Industrial and Organizational Psychology, 6, 314-332.

Albert, S., \& Whetten, D. A. (1985). Organizational identity. Research in Organizational Behavior, 7(1), 263-295.

Bansal, P., \& Song, H.-C. (2017). Similar but not the same: Differentiating corporate sustainability from corporate responsibility. Academy of Management Annals, 11(1), 105-149.

Basu, K., \& Palazzo, G. (2008). Corporate social responsibility: A process model of sensemaking. Academy of Management Review, 33(1), 122-136.

Beech, N., Burns, H., de Caestecker, L., MacIntosh, R., \& MacLean, D. (2004). Paradox as invitation to act in problematic change situations. Human Relations, 57(10), 1313-1332.

Berger, I. E., Cunningham, P., \& Drumwright, M. E. (2007). Mainstreaming corporate social responsibility: Developing markets for virtue. California Management Review, 49(4), 132-157.

Brickson, S. L. (2007). Organizational identity orientation: The genesis of the role of the firm and distinct forms of social value. Academy of Management Review, 32(3), 864-888.

Brooks, S. (2005). Corporate social responsibility and strategic management: The prospects for converging discourses. Strategic Change, 14(7), 401-411.

Carriga, E., \& Mele, D. (2004). Corporate social responsibility: Mapping the territory. Journal of Business Ethics, 53(1), 53-71.

Carroll, A. B. (1979). A three-dimensional conceptual model of corporate performance. Academy of Management Review, 4(4), 467-505.

Crilly, D., Zollo, M., \& Hansen, M. T. (2012). Faking it or muddling through? Understanding decoupling in response to stakeholder pressures. Academy of Management Journal, 55(6), 1429-1448.

de Jong, M. D. T., \& van der Meer, M. (2015). How does it fit? Exploring the congruence between organizations and their corporate social responsibility (CSR) activities. Journal of Business Ethics, 143(1), 71-83.

Denis, J.-L., Lamothe, L., \& Langley, A. (2001). The dynamics of collective leadership and strategic change in pluralistic organizations. Academy of Management Journal, 44(4), 809-837.

Gao, J., \& Bansal, P. (2013). Instrumental and integrative logics in business sustainability. Journal of Business Ethics, 112(2), 241-255.

Gioia, D. A., Corley, K. G., \& Hamilton, A. L. (2013). Seeking qualitative rigor in inductive research: Notes on the Gioia methodology. Organizational Research Methods, 16(1), 15-31. 
Gond, J.-P., Cabantous, L., \& Krikorian, F. (2018). How do things become strategic? 'Strategifying' corporate social responsibility. Strategic Organization, 16(3), 241-272.

Hahn, T., Figge, F., Pinkse, J., \& Preuss, L. (2010). Trade-offs in corporate sustainability: You can't have your cake and eat it. Business Strategy and the Environment, 19(4), 217-229.

Hahn, T., Figge, F., Pinkse, J., \& Preuss, L. (2018). A paradox perspective on corporate sustainability: Descriptive, instrumental, and normative aspects. Journal of Business Ethics, 148(2), 235-248.

Hahn, T., Pinkse, J., Preuss, L., \& Figge, F. (2015). Tensions in corporate sustainability: Towards an integrative framework. Journal of Business Ethics, 127(2), 297-316.

Hahn, T., Pinkse, J., Preuss, L., \& Figge, F. (2016). Ambidexterity for corporate social performance. Organization Studies, 37(2), 213-235.

Hahn, T., Preuss, L., Pinkse, J., \& Figge, F. (2014). Cognitive frames in corporate sustainability: Managerial sensemaking with paradoxi$\mathrm{cal}$ and business case frames. Academy of Management Review, 39(4), 463-487.

Halme, M., \& Laurila, J. (2009). Philanthropy, integration or innovation? Exploring the financial and societal outcomes of different types of corporate responsibility. Journal of Business Ethics, 84(3), 325-339.

Hengst, I.-A., Jarzabkowski, P., Hoegl, M., \& Muethel, M. (2020). Toward a process theory of making sustainability strategies legitimate in action. Academy of Management Journal, 63(1), 246-271.

Husted, B. W. (2003). Governance choices for corporate social responsibility: To contribute, collaborate or internalize? Long Range Planning, 36(5), 481-498.

Ingham, M., \& Havard, C. (2017). CSR as strategic and organizational change at "Groupe la Poste". Journal of Business Ethics, 146(3), $563-589$.

Ivory, S. B., \& Brooks, S. B. (2018). Managing corporate sustainability with a paradoxical lens: Lessons from strategic agility. Journal of Business Ethics, 148(2), 347-361.

Jarzabkowski, P. A., \& Le, J. K. (2016). We have to do this and that? You must be joking: Constructing and responding to paradox through humor. Organization Studies, 38(3-4), 433-462.

Jarzabkowski, P., Lê, J. K., \& Van de Ven, A. H. (2013). Responding to competing strategic demands: How organizing, belonging, and performing paradoxes coevolve. Strategic Organization, 11(3), $245-280$

Jay, J. (2013). Navigating paradox as a mechanism of change and innovation in hybrid organizations. Academy of Management Journal, 56(1), 137-159.

Jones, P., Comfort, D., \& Hillier, D. (2006). Corporate social responsibility and the UK construction industry. Journal of Corporate Real Estate, 8(3), 134-150.

Jones, T. M., Felps, W., \& Bigley, G. A. (2007). Ethical theory and stakeholder-related decisions: The role of stakeholder culture. Academy of Management Journal, 32(1), 137-155.

Lantos, G. P. (2001). The boundaries of strategic corporate social responsibility. Journal of Consumer Marketing, 18(7), 595-632.

Lewis, M. W. (2000). Exploring paradox: Toward a more comprehensive guide. Academy of Management Review, 25(4), 760-776.

Lindgreen, A., Swaen, V., \& Johnston, W. J. (2009). Corporate social responsibility: An empirical investigation of U.S. organizations. Journal of Business Ethics, 85(2), 303-323.

Lohne, J., Shirkavand, I., Firing, M., Schneider, K., \& Lædre, O. (2015). Ethics in commissioning in construction. Procedia Economics and Finance, 21, 256-263.

Lüscher, L. S., \& Lewis, M. W. (2008). Organizational change and managerial sensemaking: Working through paradox. Academy of Management Journal, 51(2), 221-240.

Maon, F., Lindgreen, A., \& Swaen, V. (2009). Designing and implementing corporate social responsibility: An integrative framework grounded in theory and practice. Journal of Business Ethics, 87(1), 71-89.

Maon, F., Lindgreen, A., \& Swaen, V. (2010). Organizational stages and cultural phases: A critical review and a consolidative model of corporate social responsibility development. International Journal of Management Reviews, 12(1), 20-38.

Margolis, J. D., \& Walsh, J. P. (2003). Misery loves companies: Rethinking social initiatives by business. Administrative Science Quarterly, 48(2), 268-305.

McWilliams, A., Siegel, D. S., \& Wright, P. M. (2006). Corporate social responsibility: Strategic implications. Journal of Management Studies, 43(1), 1-18.

Mirvis, P., \& Googins, B. (2006). Stages of corporate citizenship. California Management Review, 48(2), 104-126.

Montiel, I. (2008). Corporate social responsibility and corporate sustainability. Organization \& Environment, 21(3), 245-269.

Ozanne, L. K., Phipps, M., Weaver, T., Carrington, M., Luchs, M., Catlin, J., et al. (2016). Managing the tensions at the intersection of the triple bottom line: A paradox theory approach to sustainability management. Journal of Public Policy \& Marketing, 35(2), 249-261.

Poole, M. S., \& van de Ven, A. H. (1989). Using paradox to build management and organization theories. Academy of Management Review, 14(4), 562-578.

Porter, M. E., \& Kramer, M. R. (2002). The competitive advantage of corporate philanthropy. Harvard Business Review, 80(12), 56-68.

Porter, M. E., \& Kramer, M. R. (2006). Strategy and society: The link between competitive advantage and corporate social responsibility. Harvard Business Review, 84(12), 78-92.

Porter, M. E., \& Kramer, M. R. (2011). Creating shared value: How to reinvent capitalism and unleash a wave of innovation and growth. Harvard Business Review, 89(1), 66-72.

Putnam, L. L., Fairhurst, G. T., \& Banghart, S. (2016). Contradictions, dialectics, and paradoxes in organizations: A constitutive approach. The Academy of Management Annals, 10(1), 65-171.

Reidenbach, R. E., \& Robin, D. P. (1991). A conceptual model of corporate moral development. Journal of Business Ethics, 10(4), 273-284.

Rossouw, G. J., \& van Vuuren, L. J. (2003). Modes of managing morality: A descriptive model of strategies for managing ethics. Journal of Business Ethics, 46, 389-402.

Scherer, A. G., Palazzo, G., \& Seidl, D. (2013). Managing legitimacy in complex and heterogeneous environments: Sustainable development in a globalized world. Journal of Management Studies, 50(2), 259-284.

Silverman, D. (1993). Interpreting Qualitative Data: Methods for Analyzing Talk. Sage, London, UK: Text and Interaction.

Smith, W. K. (2014). Dynamic decision making: A model of senior leaders managing strategic paradoxes. Academy of Management Journal, 57(6), 1592-1623.

Smith, W. K., Gonin, M., \& Besharov, M. L. (2013). Managing socialbusiness tensions: A review and research agenda for social enterprise. Business Ethics Quarterly, 23(3), 407-442.

Smith, W. K., \& Lewis, M. W. (2011). Toward a theory of paradox: A dynamic equilibrium model of organizing. Academy of Management Review, 36(2), 381-403.

Strauss, A., \& Corbin, J. (1998). Basics of Qualitative Research. Thousand Oaks, CA: Sage.

Vaara, E., \& Whittington, R. (2012). Strategy-as-practice: Taking social practices seriously. The Academy of Management Annals, 6(1), 285-336.

Vallaster, C., Maon, F., Lindgreen, A., \& Vanhamme, J. (2019). Serving multiple masters: The role of micro-foundations of dynamic capabilities in addressing tensions in for-profit hybrid organizations. Organization Studies. https://doi.org/10.1177/0170840619 856034. 
Van der Byl, C. A., \& Slawinski, N. (2015). Embracing tensions in corporate sustainability. Organization \& Environment, 28(1), 54-79.

Weaver, G. R., Treviño, L. K., \& Cochran, P. L. (1999a). Corporate ethics practices in the mid-1990's: An empirical study of the Fortune 1000. Journal of Business Ethics, 18(3), 283-294.

Weaver, G. R., Treviño, L. K., \& Cochran, P. L. (1999b). Integrated and decoupled corporate social performance: Management commitments, external pressures, and corporate ethics practices. Academy of Management Journal, 42(5), 539-552.

Wheeler, D., Fabig, H., \& Boele, R. (2002). Paradoxes and dilemmas for stakeholder responsive firms in the extractive sector: Lessons from the case of Shell and the Ogoni. Journal of Business Ethics, 39(3), 297-318.

Yuan, W., Bao, Y., \& Verbeke, A. (2011). Integrating CSR initiatives in business: An organizing framework. Journal of Business Ethics, 101(1), 75-92.

Publisher's Note Springer Nature remains neutral with regard to jurisdictional claims in published maps and institutional affiliations. 